\title{
Continuity and intensity of shock in one-way avoidance learning in the rat
}

\author{
STEPHEN E. DIETER \\ Northern Illinois University, DeKalb, Illinois 60115
}

\begin{abstract}
Six groups of rats $(n=16)$ differed with respect to the continuity of shock (continuous or discontinuous) and the shock intensity $(.3, .8$, or $1.6 \mathrm{~mA})$ used during 65 one-way avoidance-conditioning trials. In general, a facilitative effect on one-way avoidance learning was obtained for continuous as opposed to discontinuous shock and for strong as opposed to weak shock. For both variables, the results are opposite to those obtained in discriminated shuttlebox-avoidance and barpress avoidance tasks. The data support an interpretation of the effect of continuity of shock which holds that discontinuous shock is, in effect, less intense than continuous shock. This interpretation allows the effects of the continuity-of-shock variable to be incorporated within the effective reinforcement theory of avoidance learning which has been proposed to account for shock-intensity effects in various avoidance tasks.
\end{abstract}

Discontinuous shock has been found to facilitate discriminated avoidance learning relative to continuous shock in both barpress avoidance (e.g., D'Amato \& Fazzaro, 1966; Hurwitz, 1964) and shuttlebox-avoidance (Moyer \& Chapman, 1966) tasks. Two interpretations of the continuity-of-shock effect have been offered, one based on stimulus generalization and the other on the punishment of freezing.

The stimulus generalization interpretation (D'Amato \& Fazzaro, 1966; D'Amato, Keller, \& Biederman, 1965 ) holds that the stimuli present during the shock-off periods of discontinuous shock are highly similar to the stimuli present during the CS-US interval. As a result, escape responses which occur during shock-off periods should, through stimulus generalization, come to occur during the CS-US interval. Thus, avoidance responding should increase in frequency with discontinuous shock. With continuous shock, escape responses would not be expected to show such generalization because they would be made only during shock-on periods. This interpretation has been infirmed by data which indicate that the continuity-of-shock effect occurs even if the amount of generalization which should occur when shock is discontinuous is limited by presenting shock contiguous with escape responses (Hess \& Shafer, 1968) or by terminating the CS immediately following the CS-US interval (Biederman,

\footnotetext{
This article is based on a thesis submitted in partial fulfillment of the requirements for the master's degree at Northern Illinois University. Support for this research was provided in part by Research Grant BMS71-00845 from the National Science Foundation to W. R. McAllister and D. E. McAllister, whom the author thanks for their assistance during all phases of the research. These data were reported at the meeting of the Midwestern Psychological Association, Chicago, May 1975. Reprints may be obtained from Stephen E. Dieter, Department of Psychology, Northern Illinois University, DeKalb, Illinois 60115.
}

1969). It was later contended that, rather than generalization, it was some unspecified inherent property of discontinuous shock which led to facilitation (D'Amato, Etkin, \& Fazzaro, 1968).

The freezing-punishment interpretation (Bintz, Kellicutt, \& Peacock, 1970) holds that freezing, a response which interferes with avoidance responding, can be reduced in frequency by punishment. If freezing occurs in situations where shock is administered, discontinuous shock would allow freezing to be punished several times within a single escape trial, whereas with continuous shock freezing could be punished only once per trial. On this basis, discontinuous shock would increase the probability of an avoidance response over that which would be obtained with continuous shock. Consistent with their position, Bintz et al. reported facilitated avoidance responding by rats given shocks contingent upon freezing when compared to yoked controls which received noncontingent shocks.

In contrast to the above interpretations, it is proposed here that the continuity-of-shock effect is due to discontinuous shock being, in effect, less intense than continuous shock. The reasoning is that the total duration of discontinuous shock is short relative to the duration of continuous shock. Support for the intensity position is provided by the data of Overmier (1966a, 1966b) and Riess and Farrar (1973), which indicate that the duration of a shock US is positively related to the amount of classical conditioning. An implication of the intensity interpretation is that the effects on avoidance performance of discontinuous relative to continuous shock should be the same as the effects of weak relative to strong shock. In discriminated shuttlebox-avoidance and barpress avoidance tasks, performance is better with weak than with strong shock (e.g., D'Amato \& Fazzaro, 1966; McAllister, McAllister, \& Douglass, 
1971; Moyer \& Korn, 1964), whereas the opposite effect is found in a one-way task (Moyer \& Korn, 1966). Similarly, in discriminated shuttlebox-avoidance and barpress avoidance tasks, performance is better with discontinuous than with continuous shock (e.g., D'Amato \& Fazzaro, 1966; Hurwitz, 1964; Moyer \& Chapman, 1966). It follows from the intensity position that in a one-way avoidance task performance would be poorer with discontinuous than with continuous shock. This latter prediction would not be made by the other interpretations of the effects of the continuity-of-shock variable. The stimulus generali.zation interpretation would predict that discontinuous shock would facilitate one-way avoidance performance, whereas the freezing-punishment interpretation would predict that continuity of shock would have little or no effect since it is generally held that little or no freezing occurs during one-way avoidance.

The purpose of the present experiment, which employed a one-way avoidance task, was to evaluate empirically the relative merits of these several positions.

\section{METHOD}

\section{Subjects and Design}

The subjects were 96 naive female, hooded rats 99-118 days of age, from the departmental colony. They were randomly assigned to six groups of 16 subjects each. The groups differed with respect to the continutty of shock and the shock intensity used during one-way avoldance-conditioning trials. For three groups, the shock was continuous; for the other three, it was discontinuous. Within each continuity-of-shock condition, the shock intensity was $.3, .8$, or $1.6 \mathrm{~mA}$ (nominal values). Three additional subjects were discarded, one for experimenter error (.8-mA continuous-shock group) and two for failing to respond within $60 \mathrm{sec}$ on 10 consecutive trials (.3-mA discontinuous-shock group). The subjects were housed in pairs in the colony room during the experiment and received food and water on an ad-lib basis.

\begin{abstract}
Apparatus
The apparatus consisted of a startbox, $222 \times 165 \times 152 \mathrm{~mm}$, and a safe box, $279 \times 114 \times 127 \mathrm{~mm}$. The two boxes were separated by a wall containing a guillotine door, $63 \mathrm{~mm}$ wide $\times$ $89 \mathrm{~mm}$ high, restıng on a hurdle, $63 \mathrm{~mm}$ above the floor of the startbox and $38 \mathrm{~mm}$ above the floor of the safe box. This door was located on one of the $222-\mathrm{mm}$ sides of the startbox and on one of the 114-mm sides of the safe box. The startbox was painted white, except for a blackdoor located on one of the $165-\mathrm{mm}$ sides of the box. This door remained closed throughout the present experiment. The startbox had a grid floor made of 18 stainless steel rods of $3-\mathrm{mm}$ diam spaced $13 \mathrm{~mm}$ apart. Scrambled shock was delivered through the grid floor by a Grason-Stadler shock generator, Model 700 . The safe box was painted gray and had a solid wooden floor hinged to serve as a floor switch. Hinged to the top of each of the two boxes were separate boxes which served as lids and contained light sources. The bottom of the startbox lid consisted of hardware cloth, $86 \mathrm{~mm}$ above which was a pane of ground glass; the bottom of the safebox lid was translucent plastic. The illumination was $21.52 \mathrm{~lx}$ in the startbox and $6.46 \mathrm{~lx}$ in the safe box.
\end{abstract}

\section{Procedure}

The experimental procedures required 2 days for each subject.
Day 1 consisted of a $5-\mathrm{min}$ handling session, durıng which the subject was alternately picked up and petted and placed on a table to explore.

On Day 2, each subject recelved 65 one-way avoldance conditioning trials with one of the combinations of contunuity of shock and shock intensity On each trial, the subject was placed in the center of the startbox facing the wall to the right of that which contained the guillotine door separating the start from the safe box. Forty seconds after the subject was placed in the startbox, the gullotine door was rased and a Hunter Klockounter was simultaneously activated. The raising of the guillotine door served as the CS. Shock, either continuous or discontinuous, was administered if the subject did not leave the startbox within $5 \mathrm{sec}$ after the opening of the guillotine door. Under the continuousshock condition, shock was not terminated until the subject left the startbox or until $60 \mathrm{sec}$ had elapsed. Under the discontinuousshock condition, shock was presented in successive $.25-\mathrm{sec}$ on, 2.00 -sec off intervals, the durations of which were controlled by Hunter tımers. The series of shock-on and shock-off periods was continued until the subject left the startbox or until $60 \mathrm{sec}$ had elapsed. In both continuity-of-shock conditions, responses prior to initial shock onset were designated as avoidance responses, and responses following shock onset, as escape responses.

The time elapsing from the raising of the gullotine door to the depression of the safe-box floor was measured with a Hunter Klockounter in units of $.01 \mathrm{sec}$. The guillotine door was closed immediately following an avoidance or an escape response, and $10 \mathrm{sec}$ later the subject was returned to the startbox for $40 \mathrm{sec}$ before the next trial was begun. If the subject did not respond in $60 \mathrm{sec}$, the performance was classified as a "no-escape" response. On these no-escape trials, the guillotine door was lowered, the subject was removed from the startbox, placed in the safe box, and a $60-\mathrm{sec}$ latency was recorded. The subject remained in the safe box for $10 \mathrm{sec}$ before being returned to the startbox. If a subject had 10 consecutive no-escape trials, it was discarded.

\section{Methodological Comment}

During pilot research for the present experiment the acquisition of one-way avoidance responding was found to be extremely rapid for all conditions. It became apparent that the experimental treatments were not differentially affecting the level of performance. Two aspects of the pilot procedure were identified as potential contributors to the high level of performance. These were: (a) allowing subjects to explore the safe box prior to avoldance training, and (b) during avoidance training, allowing subjects to spend the intertrial interval (ITI) in a holding box instead of the startbox after removal from the safe box. Previous data had shown that hurdle jumping in an escape-from-fear task was facilitated by having subjects jump into a familiar, as opposed to a novel, safe box (McAllister \& McAllister, 1967) and by having subjects spend the ITI in a holding box rather than placing them immediately back in the startbox after removal from the safe box (McAllister, McAllister, Brooks, \& Goldman, 1972). In order to degrade performance so that any effects of the experimental treatments could be detected, the two mentioned procedures were changed. Thus, there was no exploration of the apparatus prior to the experiment, and during avoidance iraining, subjects were returned to the startbox instead of to a holding box to spend the ITI. As the results indicate, these procedural changes were effective in lowering the performance level so that the effect of the manipulated variables could be discerned.

\section{RESULTS}

The basic data for each subject consisted of three measures: percentage of avoidances in blocks of five trials, number of trials before the first avoidance, and the trial of last error (last escape response). 


\section{Percentage of Avoidances in Blocks of Five Trials}

The mean percentage of avoidances in blocks of five trials is plotted separately for each group in Figure 1. Avoidance performance improved with trials, then leveled off for each group. There was a tendency toward poorer performance with discontinuous than with continuous shock throughout training in the .3-mA shock condition and at the end of training under the 1.6-mA condition. Little difference was apparent between the two continuities of shock for the .8-mA groups.

In order to analyze the effects of the experimental treatments over trials, a repeated measures analysis of variance was performed with Continuity of Shock and Shock Intensity as the between-subjects factors and Trial Blocks (1-13) as the within-subject factor. Reflecting the learning which took place in each of the groups, the Trial Blocks factor was significant, $\mathrm{F}(12,1080)=156.87, \mathrm{p}<.001$, and did not interact significantly with the other factors. Also significant were the between-subjects factors, Continuity of Shock, $F(1,90)=4.64, p<.05$, and Shock Intensity, $F(2,90)=19.44, p<.001$. As indicated by the grand means plotted in Figure 2, performance was superior with continuous than with discontinuous shock, and performance improved as shock intensity increased. Multiple comparisons using the NewmanKeuls technique indicated that performance with .3-mA shock was significantly inferior to that with .8- and 1.6-mA shock. Performance under the latter two conditions did not differ.

The interaction between continuity of shock and shock intensity was not significant. Such an interaction is suggested, however, in Figure 2. Perusal of the data suggested that this figure was somewhat misleading, because the grand mean of the $.8-\mathrm{mA}$ continuous-shock group was lowered considerably by the performance of a single subject which made $44.62 \%$ avoidances relative to a group mean of

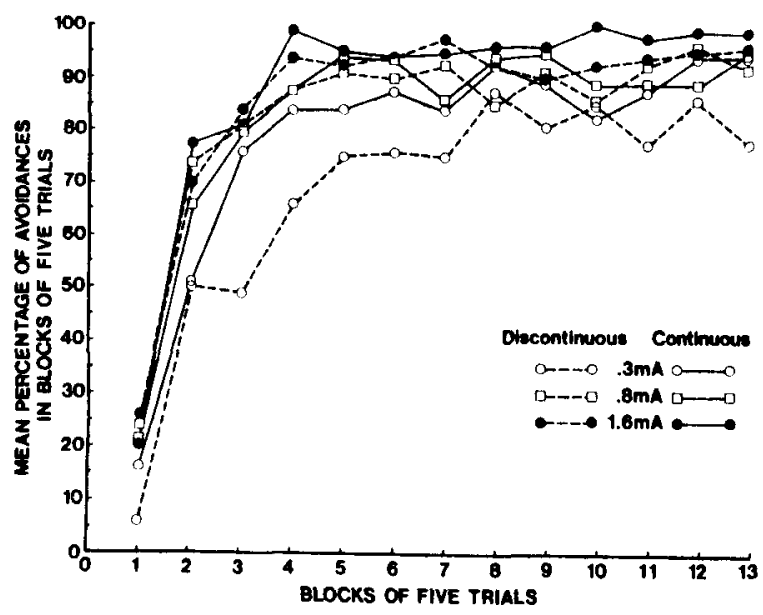

Figure 1. Mean percentage of avoidances in blocks of five trials for Trial Blocks 1-13 for each group.

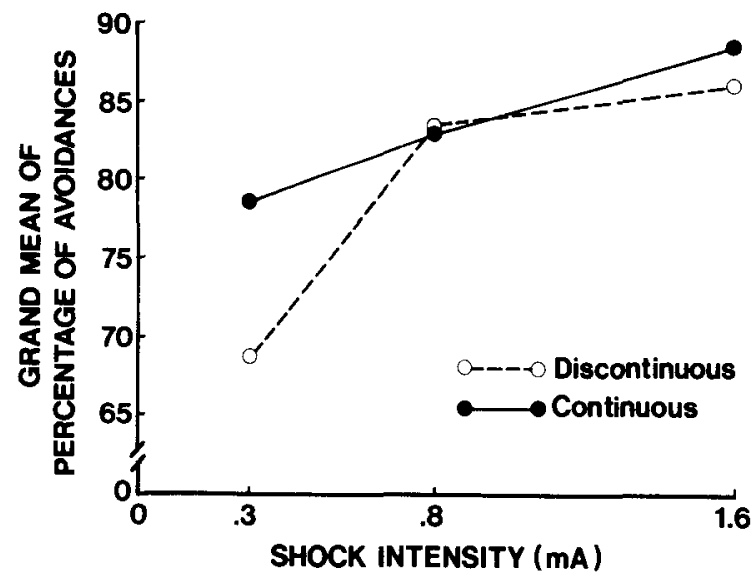

Figure 2. Grand mean of percentage of avoidances over 65 trials for each group.

$82.98 \%$ avoidances. With this subject excluded, the mean of the .8-mA continuous-shock group is $85.54 \%$.

\section{Number of Trials Before the First Avoidance}

The mean number of trials before the first avoidance for each group is plotted in Figure 3. It can be seen that performance with continuous shock was superior to that with discontinuous shock only with .3-mA shock and that only with discontinuous shock did performance improve when shock intensity was increased. Statistical analyses confirmed these observations. In a 2 by 3 factorial analysis of variance, the interaction between Continuity of Shock and Shock Intensity was significant, $F(2,90)=6.52$, $\mathrm{p}<.005$. Subsequent simple effects analyses indicated that Continuity of Shock was significant only for the $.3-\mathrm{mA}$ groups, $F(1,30)=7.82, \mathrm{p}<.01$, and that Shock Intensity was significant only for the discontinuous-shock groups, $F(2,45)=9.20, p<.001$. Multiple comparisons of the discontinuous-shock groups using the Newman-Keuls technique indicated that the performance of the .3-mA group was significantly inferior to that of both the .8- and 1.6-mA groups, which did not differ.

\section{Trial of Last Error}

Figure 4 presents the mean trial of last error (last failure to avoid) for each group. This measure reflects the speed with which complete mastery of the task was achieved. It can be seen from the figure that the last error was made earlier with strong than with weak shock and with continuous than with discontinuous shock. A 2 by 3 factorial analysis of variance with Continuity of Shock and Shock Intensity as the factors confirmed these observations. The analysis yielded significant effects for both Continuity of Shock, $F(1,90)=17.44, p<.001$, and Shock Intensity, $F(2,90)=5.46, p<.01$. The interaction was not significant. Subsequent multiple 


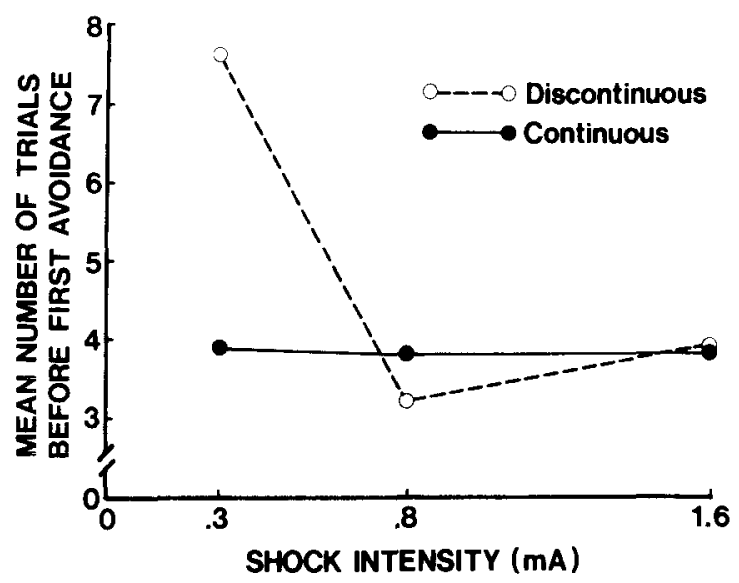

Figure 3. Mean number of trials before first avoidance for each group.

comparisons of the shock-intensity effect using the Newman-Keuls technique showed performance under the .3-mA shock condition to be inferior to that under the 1.6-mA condition. The $.8-\mathrm{mA}$ shock condition did not differ significantly from either of the other two conditions.

\section{DISCUSSION}

In general, a facilitative effect on one-way avoidance learning was obtained for continuous as opposed to discontinuous shock and for strong as opposed to weak shock. The latter result replicates the finding of Moyer and Korn (1966). One qualification should be noted regarding the generalization that performance increased with shock intensity. That is the failure to find an effect of shock intensity for continuous shock with the trials-to-first-avoidance measure. However, it seems likely that had lower intensities of continuous shock been employed an effect like that found with discontinuous shock would have been obtained.

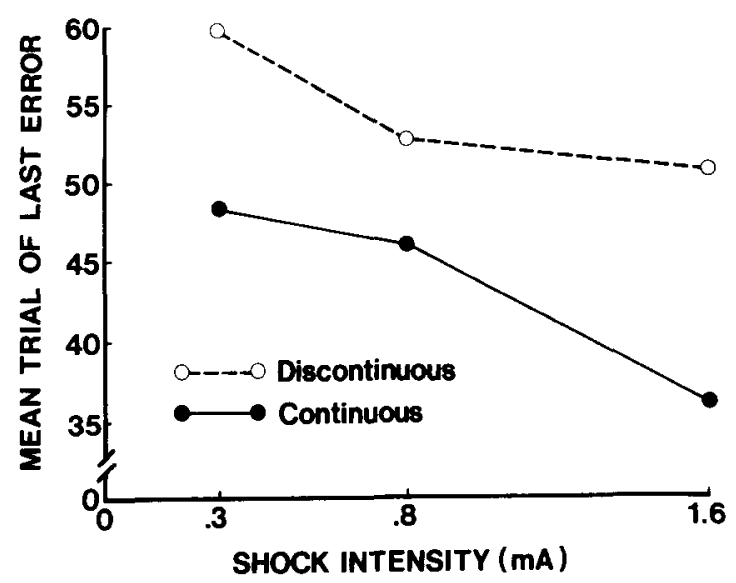

Figure 4. Mean trial of last error for each group.
The present finding, that discont nuous shock leads to poorer performance than continuous shock in the one-way avoidance task, contrasts with the facilitative effect of discontinuous shock obtained in discriminated shuttlebox-avoidance and barpress avoidance tasks. An adequate theoretical account of the effects of this variable has to accommodate these disparate results. Neither the stimulus generalization nor the freezing-punishment interpretations meet this requirement. As explained above, the stimulus generalization interpretation predicts facilitation of avoidance performance by discontinuous as opposed to continuous shock regardless of the task. The freezing-punishment interpretation also predicts better performance in the shuttlebox and barpress tasks but would probably predict that one-way avoidance would be affected little, if at all, by the continuity-of-shock variable.

On the other hand, the results obtained in these various tasks would be expected if discontinuous shock is considered to be, in effect, less intense than continuous shock. Thus, in a given task, the differential effect on performance of discontinuous as opposed to continuous shock should be the same as that of weak as opposed to strong shock. These expectations are supported by the data: Strong relative to weak shock and continuous relative to discontinuous shock facilitate avoidance performance in the one-way task, as demonstrated in the present experiment, and degrade performance in the shuttlebox and barpress tasks, as has previously been found (e.g., D'Amato \& Fazzaro, 1966; Moyer \& Chapman, 1966; Moyer \& Korn, 1964). By adopting the intensity interpretation, the effects of the continuity-of-shock variable in the various avoidance tasks can be understood within the context of the effective reinforcement theory. This theory (McAllister, McAllister, \& Dieter, 1976; McAllister et al., 1971), which was proposed to account for shock-intensity effects, assumes that the amount of effective reinforcement for an avoidance response is positively related to the amount of fear reduction occurring with the termination of fear-arousing stimuli (CS and/or situational cues) and negatively related to the amount of fear elicited by the stimuli present following a response. In a one-way avoidance task, which employs a distinctive safe box, little or no fear is present following a response. Therefore, the greater amount of fear conditioned with strong (or continuous) shock as compared to weak (or discontinuous) shock should allow for greater fear reduction and, hence, better performance. In contrast to the one-way task, in the shuttlebox or barpress task, an avoidance response does not remove the subject from the fear-arousing situational cues. With strong (or continuous) shock, more fear remains following the response than remains with weak (or discontinuous) shock. The greater amount of fear 
reduction occurring with CS termination when shock is strong (or continuous) is assumed by the theory to be more than offset by the greater amount of situational-cues fear which remains after the response. Thus, weak (or discontinuous) shock should facilitate performance in the shuttlebox and barpress avoidance tasks.

\section{REFERENCES}

Biederman, G. B. The role of discontinuous US in discriminated avoidance learning. Psychonomic Science, 1969, 16, 246-247.

Bintz, J., Kellicutr, M., \& Peacock, K. Avoidance conditioning and movement-contingent US presentation. Journal of Comparative and Physiological Psychology, $1970,72,250-256$.

D'Amato, M. R., Etkin, M., \& Fazzaro, J. Effects of shock type and intensity on anticipatory responses. Journal of Comparative and Physiological Psychology, 1968, 66, 527.529.

D'Amato, M. R., \& Fazzaro, J. Discriminated lever-press avoidance learning as a function of type and intensity of shock. Journal of Comparative and Physiological Psychology. 1966, 61, 313-315.

D'Amato, M. R., Keller, D., \& Biederman, G. Discriminated avoidance learning as a function of parameters of discontinuous shock. Journal of Experimental Psychology, $1965,70,543-548$.

Hess, J. H., \& Shafer, J. N. Discontinuous shock and generalization to the preshock period in discriminated avoidance learning. Psychonomic Science, 1968, 10, 175-176.

HURWITz, H. M. B. Method for discriminative avoidance training. Science, 1964, 145, 1070-1071.

McAllister, D. E., McAllister, W. R., Brooks, C. I., \&
Goldman, J. A. Magnitude and shift of reward in instrumental aversive learning in rats. Journal of Comparative and Physiological Psychology, 1972, 80, 490-501.

MCAllister, D. E., McAllister, W. R., \& Dieter, S. E. Reward magnitude and shock variables (continuity and intensity) in shuttlebox-avoidance learning. Animal Learning \& Behavior, 1976, 4, 204-209.

MCAllister, W. R., \& McAllister, D. E. Drive and reward in aversive learning. American Journal of Psychology, 1967, 80, 377-383.

McAllister, W. R., McAllister, D. E., \& Douglass, W. K. The inverse relationship between shock intensity and shuttlebox avoidance learning in rats: A reinforcement explanation. Journal of Comparative and Physiological Psychology, 1971, 74, 426-433.

Moyer, K. E., \& Chapman, J. A. Effect of continuous vs. discontinuous shock on shuttle box avoidance in the rat. Psychonomic Science, 1966, 4, 197-198.

MOYER, K. E., \& KorN, J. H. Effect of UCS intensity on the acquisition and extinction of an avoidance response. Journal of Experimental Psychology, 1964, 67, 352.359.

MOYER, K. E., \& KORN, J. H. Effect of UCS intensity on the acquisition and extinction of a one-way avoidance response. Psychonomic Science, 1966, 4, 121-122.

OVERMIER. J. B. Differential transfer of control of avoidance responses as a function of UCS duration. Psychonomic Science, 1966, 5, 25-26. (a)

OVERMIER, J. B. Instrumental and cardiac indices of Pavlovian fear conditioning as a function of US duration. Journal of Comparative and Physiological Psychology, 1966, 62, 15-20. (b) RuEss, D., \& FARRAR, C. H. UCS duration and conditioned suppression: Acquisition and extinction between-groups and terminal performance within-subjects. Learning and Motivation, 1973, 4, 366-373.

(Received for publication August 4, 1975; revision accepted March 10, 1976.) 